\title{
Vadose Zone Tracer Testing in the UK Sherwood Sandstone: Hydrogeophysical Data Report
}

Andrew Binley

U.S. Department of Energy

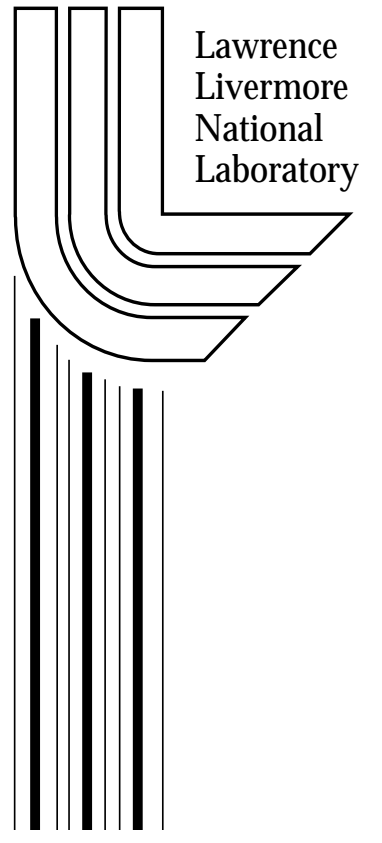

Lancaster University, Lancaster, England

September 16, 2003 


\section{DISCLAIMER}

This document was prepared as an account of work sponsored by an agency of the United States Government. Neither the United States Government nor the University of California nor any of their employees, makes any warranty, express or implied, or assumes any legal liability or responsibility for the accuracy, completeness, or usefulness of any information, apparatus, product, or process disclosed, or represents that its use would not infringe privately owned rights. Reference herein to any specific commercial product, process, or service by trade name, trademark, manufacturer, or otherwise, does not necessarily constitute or imply its endorsement, recommendation, or favoring by the United States Government or the University of California. The views and opinions of authors expressed herein do not necessarily state or reflect those of the United States Government or the University of California, and shall not be used for advertising or product endorsement purposes.

This is a preprint of a paper intended for publication in a journal or proceedings. Since changes may be made before publication, this preprint is made available with the understanding that it will not be cited or reproduced without the permission of the author. 


\title{
Vadose Zone Tracer Testing in the UK Sherwood Sandstone: Hydrogeophysical Data Report
}

\author{
Andrew Binley \\ Department of Environmental Science, \\ Lancaster University, \\ Lancaster LAI 4YQ, UK
}

10 October, 2003 


\section{Introduction.}

In 1998 a joint project between the universities of Lancaster and Leeds, funded by the UK Natural Environment Research Council and the UK Environment Agency, was initiated to examine, using geophysical methods, unsaturated flow and transport processes at two purposely developed field sites in the UK Sherwood Sandstone. More recently work by Lancaster university funded by a UK Natural Environment Research Council PhD studentship (awarded to Peter Winship) has continued the investigation at the two sites. This work, so far, has demonstrated: how crossborehole (borehole to borehole) radar tomography can be used to monitor changes in moisture content in the unsaturated zone due to natural and forced (tracer) inputs (Binley et al., 2001); the evaluation of seasonal variation of moisture content profiles using high-resolution borehole resistivity and radar profiling (Binley et al., 2002a); initial attempts to utilise the geophysical data to develop numerical predictive models of unsaturated flow (Binley et al., 2002b; Binley et al, 2003; Binley and Beven, 2003). In addition, petrophysical models relating geophysical data to hydrological properties have been developed (West et al., 2003). Here we provide a data report on two tracer experiments conducted at one of the field sites. Within the report we describe the site layout and present summary results from the two tracer tests. In the appendix a file map is provided to allow identification of relevant files in the dataset accompanying this report.

The two techniques used here are three-dimensional time-lapse electrical resistivity tomography (ERT) and lime-lapse cross-borehole radar tomography and profiling. They provide geophysical measurements that can be related to the moisture content of the subsurface, and subsequently to the conductivity of that moisture content. They also yield data on a scale that is appropriate for numerical simulations of water movement in the subsurface. The two methods have been applied at a site (Lings Farm, Hatfield, near Doncaster, UK) in the outcrop of the Sherwood Sandstone (see Figure 1).

\section{Site description}

At the Hatfield site six boreholes were drilled in 1998 in order to monitor tracers injected into the sandstone (see Figure 2). Four of these boreholes were designed for resistivity measurements (H-E1, H-E2, H-E3 and H-E4). These ERT boreholes consist of sixteen stainless steel mesh electrodes equally spaced between 2 and $13 \mathrm{~m}$ depth. Two borehole were installed for radar measurements (H-R1 and H-R2). These boreholes were drilled to a depth of $12 \mathrm{~m}$ and completed with $75 \mathrm{~mm}$ PVC casing. Both the ERT and radar boreholes have a weak sand/cement grout backfilling the gap between the host formation and installation. A tracer injection borehole was also installed (H-I2), located within the centre of the borehole array (see Figure 2). The injection borehole is $3.5 \mathrm{~m}$ deep, with a $100 \mathrm{~mm}$ diameter slotted section and gravel pack between 3 and $3.5 \mathrm{~m}$ depth.

Two cored boreholes were drilled at the site and logged by colleagues at Leeds University, see Pokar et al.(2001) for details. The location of these cores holes is shown in Figure 2 and in Figure 3 a summary lithological log is shown. The main 
interlaminated fine and medium-grained sandstones, particularly in the zone around 6 $\mathrm{m}$ depth, and between 8 and $9 \mathrm{~m}$. Drift at the top of the section at the site is typically 2 to $3 \mathrm{~m}$ thick, and consists of mainly fluvio-glacial sands (derived from the underlying sandstones) with frequent large pebbles/cobbles.

Cores were not extracted from the tracer array area to minimise disturbance, particularly from ingress of drilling fluids. However, geophysical logs were obtained for all drilled boreholes using electromagnetic induction and natural gamma logging tools. Figure 4 shows example natural gamma logs for the boreholes H-E2, H-R2, HR2 and H-E1 (for location see Figure 2). These logs reveal subtle contrasts but support the conceptualisation of repeated fine - medium sandstone layering.

Specimens from the core were extracted by Leeds University for measurement of dc resistivity and dielectric response under varying moisture contents. In order to describe the relationship between bulk dielectric constant $(\kappa)$ and moisture content $(\theta)$ for a number of samples from the core West et al. (2003) used the complex refractive index method (CRIM):

$$
\sqrt{\kappa}=(1-\phi) \sqrt{\kappa_{s}}+\theta \sqrt{\kappa_{w}}+(\phi-\theta) \sqrt{\kappa_{a}},
$$

where $\kappa_{s}$ is the dielectric constant of the sediment grains, $\kappa_{w}$ is the dielectric constant of water (assumed to be 81), $\kappa_{a}$ is the dielectric constant of air (assumed to be 1) and $\phi$ is porosity (assumed to be 0.32 , based on an average of core measurements). West et al. (2003) show that for $100 \mathrm{MHz}$ frequency measurements a value of $\kappa_{s}=5$ is appropriate for the main lithological unit of the core.

The real part of the bulk dielectric constant $(\kappa)$ is derived from the radar velocity $v$ using:

$$
\sqrt{\kappa}=\frac{c}{v}
$$

where $c$ is the radar wave velocity in air $(\approx 0.3 \mathrm{~m} / \mathrm{ns})$. Where measurements are taken at different times, equations (1) and (2) can be used to give the change in moisture content $(\Delta \theta)$ as a function of the difference in observed radar wave slowness $(\Delta(1 / v))$ :

$$
\Delta \theta=\Delta\left(\frac{1}{v}\right)\left(\frac{c}{\sqrt{\kappa_{a}}-\sqrt{\kappa_{w}}}\right) .
$$

In order to describe variation in dc resistivity with moisture content the empirical formula of Archie was used:

$$
S=\left(\frac{\rho_{s}}{\rho}\right)^{\frac{1}{m}}
$$


where $S$ is water saturation $(=\theta / \phi), \rho$ is bulk resistivity, $\rho_{\mathrm{s}}$ is bulk resistivity at $100 \%$ saturation and $m$ is an empirical constant. Using a least-squares fit to measurements of saturation and resistivity from three samples of the main lithology provided by Leeds University gives the following parameters: $m=1.13 \pm 0.027, \rho_{\mathrm{s}}=65.84 \pm 4.36$ $\Omega \mathrm{m}$ (further details may be found in Binley et al., 2002a).

For resistivity measurements repeated at different times, then:

$$
\frac{\rho_{t}}{\rho_{0}}=\frac{\theta_{t}^{-n}}{\theta_{0}^{-n}} \frac{\rho_{w, t}}{\rho_{w, 0}},
$$

where the subscripts $t$ and 0 refer to measurements at time $t$ and time 0 , respectively.

\section{Experimental procedures}

Three tracer tests have been carried out at the site. During October 1998 a water tracer was injected into the sandstone using borehole H-I2. Changes in bulk resistivity and dielectric constant of the sandstone were then monitored using 2-D cross borehole radar and 3-D cross borehole resistivity. A second tracer test was carried out during February 1999. During this test only radar and 2-D resistivity was employed. In March 2003 a third tracer test was performed using a saline tracer. During this test 2-D cross borehole radar and 3-D cross borehole resistivity measurements were carried out. We report here on the October 1998 and March 2003 experiments.

\subsection{October 1998 Tracer Test}

Transmission radar measurements were collected between boreholes H-R1 and H-R2 using the Sensors and Software Pulse EKKO radar system. Using $100 \mathrm{MHz}$ antennae, measurements were made at $0.25 \mathrm{~m}$ intervals between depths of 2 and $11.5 \mathrm{~m}$ using zero offset profile data collection mode. Radar data collected closer to the ground surface and the water table were not collected in this mode to avoid disturbance from reflected or refracted signals due to high contrast in dielectric properties at these boundaries. Both zero offset and multiple offset radar were collected.

Using all electrodes in H-E1, H-E2, H-E3 and H-E4, together with 4 supplementary surface electrodes between H-E1 and H-E2 and 4 electrodes between H-E3 and H-E4, 3-D cross-borehole measurements were made using the Geoserve Resecs resistivity instrument. A dipole-dipole measurement scheme was adopted using a current and potential dipole separation of $2.92 \mathrm{~m}$. A total of 4428 measurements were taken, one half of which were reciprocal (swapped current and potential electrodes) measurements. Data collection took approximately 4.5 hours. Collection of measurements in the reciprocal configuration permitted assessment of data error. All measurements which did not satisfy reciprocity by less than $10 \%$ were removed prior to inversion. 
Approximately 2,100 litres of tracer was injected in borehole H-I2 (see Figure 2) between 14:30 on 7 October and 13:40 on 10 October 1998, equivalent to a uniform rate of approximately 30 litres per hour. Mains supply water was used as a tracer source, with the addition of a small quantity of $\mathrm{NaCl}$ to maintain an electrical conductivity of approximately $660 \mu \mathrm{S} / \mathrm{cm}$, equivalent to observed local groundwater conductivity. Injection of the tracer was performed using a constant head device in borehole $\mathrm{H}-\mathrm{I} 2$, which maintained a $0.15 \mathrm{~m}$ (approximately) water column at the base of the borehole.

In order to assess changes due to natural inputs rainfall and evapotranspiration, MORECS (UK Meteorological Office Rainfall and Evapotranspiration Calculation System) estimates were made available from data collected at a nearby weather station. During the 10 days following start of tracer injection a total of $33 \mathrm{~mm}$ precipitation were recorded. The water table was located at $12 \mathrm{~m}$ depth.

\subsection{March 2003 Tracer Test}

Using borehole H-R1 and H-R2, two radar data collection modes were adopted: zero offset profiling (ZOP) and multiple offset gathers (MOG). For both surveys a Sensors and Software PuleEKKO PE100 system was used with $100 \mathrm{MHz}$ antennae. For the ZOP surveys the antennae were lowered at $0.25 \mathrm{~m}$ increments. For the MOG surveys a 'complete' dataset was not obtained due to time constraints imposed by the expected tracer movement. The MOG surveys carried out used transmitter locations at $1 \mathrm{~m}$ increments between depths of $1 \mathrm{~m}$ and $10 \mathrm{~m}$ in $\mathrm{H}-\mathrm{R} 1$, with receiver positions at 0.25 $\mathrm{m}$ increments between $1 \mathrm{~m}$ and $10 \mathrm{~m}$ depth in $\mathrm{H}-\mathrm{R} 2$ (also ensuring that the absolute vertical angle between transmitter and receiver did not exceed $45^{\circ}$ ).

For this experiment, a six-channel Geoserve Resecs instrument was used for ERT measurements, allowing the collection of 6,372 measurements in about two and a half hours. The current and potential electrode pairs were chosen so that the dipoles they defined were horizontal, with one of the electrodes in each dipole being in one borehole, and the other being in any of the remaining three boreholes. The current and potential dipoles were restricted to being within $4.4 \mathrm{~m}$ of each other vertically, so that measured voltages were not too low. For all ERT surveys, reciprocal data (i.e. current and potential electrodes swapped) were collected to assess error levels (repeatability checks are often inadequate for this purpose). Thus, a maximum of 3,186 measurements were used for data inversion.

The tracer consisted of 1,200 litres of water, dosed with $\mathrm{NaCl}$ to give an electrical conductivity value of $2200 \mu \mathrm{S} \mathrm{cm}^{-1}$ (groundwater electrical conductivity at the site was measured as $650 \mu \mathrm{S} \mathrm{cm}^{-1}$ ). The tracer was injected over a period of three days, from $14^{\text {th }}$ March 2003 to $17^{\text {th }}$ March 2003 at a steady rate of approximately 17 litres per hour. A float valve in the injection borehole was used to control the head in the injection borehole, and hence the flow rate. Duplicate sets of background measurements of ERT were made on $6^{\text {th }}$ March and $13^{\text {th }}$ March, and of radar measurements on $6^{\text {th }}$ March and $14^{\text {th }}$ March. Tracer flow was monitored by means of a pressure transducer in a storage tank, which gave a way of calculating the cumulative injection volume over time. During the tracer test no rainfall was observed at the site. 


\section{Example Results}

\subsection{October 1998 Tracer Test}

\subsubsection{Changes in moisture content inferred from radar measurements}

Figure 5 shows the change in moisture content inferred from the zero offset crossborehole radar measurements using Equation (3), both during and after injection of the tracer. The changing profile indicates clearly the vertical migration towards the water table. As an indicator of the movement of the tracer volume, the centre of mass of the change in moisture content was computed from the radar results. We use the centre of mass in preference to other measures, such as the position of the tracer front, as (a) it has a physical basis, and (b) will be sensitive to the hydraulic conductivity of the sandstone for gravity dominated flow such as that reported here. Figure 5 shows the centre of mass moving approximately $3 \mathrm{~m}$ from the injection source over 9 days.

\subsubsection{Changes in resistivity}

Both 3-D resistivity images were computed using a finite element based regularised weighted least squares inversion using the "Occam's" approach. For inversion of the 3 -D data, the volume enclosed by the boreholes (13m depth, 8 by $10 \mathrm{~m}$ in plan) was discretised into 5440 finite elements and parameterised into 1360 resistivity blocks, with suitable additional discretisation to account for boundary conditions at infinity. Using a pre-tracer dataset as a reference, changes in moisture content were computed using equation (4).

Figure 6 shows three-dimensional plots of two selected results from 3-D ERT analysis. Here the moisture bulb is seen to grow with time. Perhaps more useful, however, is a two-dimensional vertical slice, as shown in Figure 7. Maximum changes in moisture content of $4 \%$ (by volume) are detected shortly after tracer injection stops. Note that these are somewhat lower than predicted by the radar results in Figure 5. A peak change in moisture content of $6 \%$ by volume for the radar is integrated over a $5 \mathrm{~m}$ borehole separation and thus localised increases closer to the source will be somewhat higher. Unlike radar, ERT will suffer from reduced sensitivity away from the boreholes and, since the tracer signal in this experiment is near mid-point of the borehole array, ERT predicted changes in moisture content are likely to be underestimated. This is easily confirmed for the experiment described here, as the injected volume of water is known. In fact, computation of the (water) mass balance using the 3-D ERT results reveals an approximate (and consistent) 50\% mass balance error (that is, the moisture content change predicted by ERT underestimates the true change). Whilst it is possible to adjust the petrophysical parameters of equation (4) to minimise this error, the sensitivity of the mass balance error to the uncertainty in the Archie parameters is reasonably small and cannot be considered as the main error source. The error is more likely attributed to reduced sensitivity of ERT with distance from the boreholes. Despite this, the vertical migration of the tracer shown in Figure 6 shows consistency with radar and ERT results. 


\subsection{March 2003 Tracer Test}

\subsubsection{Changes in moisture content inferred from radar measurements}

As changes in radar velocity are not dependent on lithological parameters in the petrophysical model (see equation (5)), changes in moisture content may be determined more reliably than absolute moisture content. Changes in moisture content from the pre-tracer conditions, inferred from the ZOP surveys, are shown in Figure 7. The development of the tracer plume during the injection $\left(14^{\text {th }}\right.$ March to $17^{\text {th }}$ March) is clearly seen, as is the steady vertical migration of the wetting front.

As this wetting front moves, the moisture 'bulb' grows and thus the volumetric change in water content observed by the radar decreases over time. The volume of the subsurface which is 'sensed' by the radar profile is described by the Fresnel zone for the particular radar wave frequency. The Fresnel zone is assumed to be an ellipse with a minor axis length of:

$$
B=\left(\frac{\lambda^{2}}{4}+L \times \lambda\right)^{0.5}
$$

and a major axis length of

$$
A=\left(\frac{\lambda}{2}+L\right),
$$

where $L$ is the borehole separation $(5 \mathrm{~m}$ ) and $\lambda$ is the wavelength (for a $100 \mathrm{MHz}$ wave, with a velocity of about $0.1 \mathrm{~m} \mathrm{~ns}^{-1}$ this is $1 \mathrm{~m}$ ). For the case reported here, $B=$ $1.12 \mathrm{~m}$ and $A=5.5 \mathrm{~m}$ (see Figure 8).

The changes in moisture content, determined from the ZOP surveys, are shown in Figure 9 as hydrographs at particular depths. These time-series reveal that after approximately 230 hours (about 9 days) after injection of the tracer was terminated (i.e. about 300 hours after the start of tracer injection) moisture contents at depths of 5 $\mathrm{m}$ and $6 \mathrm{~m}$ return to near pre-tracer levels. At greater depths, however, the retention of moisture is observed for considerably longer. We infer this to be a result of fine grained units between $8 \mathrm{~m}$ and $9 \mathrm{~m}$ depth (see Figures 3 and 4).

\subsubsection{Changes in resistivity}

The changes in moisture content determined from the radar profiles offer some insight into the mechanisms controlling unsaturated flow within the sandstone at the site, however, it is impossible to determine travel times of 'parcels' of water directly from these observations. Moisture, already retained in the sandstone will be displaced by tracer water but clearly 'new' and 'old' water cannot be differentiated. It is for this reason that electrical resistivity surveys were utilised. As already stated, changes in resistivity will be related to changes in moisture content and pore water electrical conductivity (see equation (3)). With appropriate petrophysical relationships we may therefore use ERT and radar jointly to differentiate the 'new' tracer water from the existing formation water. 
The changes in resistivity throughout the tracer test are shown in Figure 10. These are shown as isosurfaces of volumes with changes relative to the pre-tracer conditions above a certain threshold (in this case $7.5 \%$ ). The images show clearly the development of the tracer 'bulb' during the injection and the subsequent vertical migration. Most striking is the obvious lateral spreading of the tracer between 8 and 9 $\mathrm{m}$ depth. These support the hypothesis of a hydraulically retarding 'layer' at this depth. Note also, in Figure 10, that near the tracer injection source (between depths of 3.5 to $6 \mathrm{~m}$ ) the resistivity does not return to pre-tracer values even by $2^{\text {nd }}$ April. The volume apparently occupied by the tracer in this depth interval does shrink over the monitoring period but is still detectable 16 days after the tracer injection was stopped. To depths of $6 \mathrm{~m}$, the moisture content has returned to pre-tracer levels by $27^{\text {th }}$ March (see Figure 6); the change in resistivity is thus an indication of that some fraction of the pore space has been replaced by the more electrically conductive tracer fluid.

\subsubsection{Changes in pore water solute concentration}

If we assume that the solute concentration of pore water is linearly related to the fluid electrical conductivity, i.e. inversely related to the fluid resistivity $\rho_{w}$, then equations (1) and (5) can be combined to give an expression for the solute concentration relative to the background (pre-tracer) levels,

$$
\frac{C_{t}}{C_{0}}=\frac{\rho_{0}}{\rho_{t}}\left(\frac{\sqrt{\kappa_{0}}+\phi\left(\sqrt{\kappa_{s}}-\sqrt{\kappa_{a}}\right)-\sqrt{\kappa_{s}}}{\sqrt{\kappa_{t}}+\phi\left(\sqrt{\kappa_{s}}-\sqrt{\kappa_{a}}\right)-\sqrt{\kappa_{s}}}\right)^{n},
$$

where $C_{0}$ and $C_{t}$ represents the solute concentration at time 0 and time $t, \kappa_{0}$ and $\kappa_{t}$ are the dielectric constant values at time 0 and time $t$.

Assuming a value of $n=1.13$ (equation (4)) and other values defined as before, the resistivity quotient $\left(\rho_{0} / \rho_{t}\right)$ were interpolated from the ERT images onto the vertical plane between radar boreholes H-R1 and H-R2. Then using changes in dielectric constant obtained from the MOG radar inversions the ratios of the pore water solute concentrations were computed. The result is shown in Figure 11, from which it is apparent that the solute migrates at a much slower rate than the moisture front (as expected). Early transport is rapid to a depth of $6 \mathrm{~m}$, at which point vertical transport is retarded somewhat - again supporting the hypothesis that the observed fine grained units act as hydraulically impeding layers. We recognise that the results produced from application of equation (8) are subject to errors; increases in concentration above the tracer injection zone, for example, are apparent in Figure 11. Nevertheless, this analysis offers some insight into unsaturated zone solute transport processes that could not have been achieved without joint application of radar and resistivity.

\section{Summary}

Cross-borehole radar and resistivity measurements have been used to characterise changes in moisture content and solute concentration due to controlled injection of water and saline tracers in the unsaturated zone of the Sherwood Sandstone. Borehole radar transmission profiles show the vertical migration of the wetting front during the tracer test. Changes down to $1 \%$ volumetric moisture content appear detectable by 
achievable at all field sites. Three-dimensional cross-borehole electrical resistivity tomography was deployed to monitor changes in resistivity over time. The results show clearly the plume development and have revealed the impact of a hydraulically impeding layer above the water table. Geophysical and geological logs acquired at the site support this conceptualisation. By combining the resistivity tomograms with cross-borehole radar tomograms we have estimated changes in pore water concentration over time, albeit in a two-dimensional vertical plane. Such information would not be obtainable without the joint application of radar and resistivity methods. By utilising these in cross-borehole mode high-resolution imaging has been achievable. 


\section{Acknowledgements}

All site operations were managed by Peter Winship. We are grateful the Environment Agency, UK for continued support for our work. Ted Mould and Albert Walmsley (Environment Agency, UK) brought drilling expertise early on in the project. The work would not have been possible without agreement of site access by John Cunliffe of Lings Farm, Hatfield. Jared West supplied core logs and saturation-dc resistivity data. This work was funded by the Natural Environment Research Council, UK under NERC studentship grant NER/S/A/2001/06246. The preparation of this data report and the preparation of the accompanying data package was funded by the Laboratory Directed Research and Development Program at Lawrence Livermore National Laboratory.

\section{References}

Binley, A. and K. Beven, 2003, Vadose zone flow model uncertainty as conditioned on geophysical data, Ground Water, 41(2), 119-127.

Binley, A., G. Cassiani and P. Winship, 2003, Characterization of heterogeneity in unsaturated sandstone using borehole logs and cross-borehole tomography, in Aquifer Characterization by Bridge and Hyndman (Eds.), SEPM, Society for Sedimentary Geology (in press).

Binley, A., P. Winship, L.J. West, M. Pokar and R.Middleton, 2002a, Seasonal Variation of Moisture Content in Unsaturated Sandstone Inferred from Borehole Radar and Resistivity Profiles, J. Hydrol. 267(3-4), 160-172.

Binley, A., G. Cassiani, R. Middleton and P. Winship, 2002b, Vadose zone model parameterisation using cross-borehole radar and resistivity imaging, J. Hydrol. 267(34), 147-159.

Binley, A., P. Winship, R. Middleton, M. Pokar and J. West, 2001, High resolution characterization of vadose zone dynamics using cross-borehole radar, Water Resour. Res., 37(11), 2639-2652.

Pokar, M., L.J. West, P. Winship and A.M. Binley, 2001, Proceedings of the Symposium on Applications of Geophysics to Engineering and Environmental Problems (SAGEEP2001)Proceedings of the Symposium on Applications of Geophysics to Engineering and Environmental Problems (SAGEEP2001), Environmental and Engineering Geophysical Society, Denver, CO (2001).

West, L.J., K. Handley , Y. Huang and M. Pokar, 2003, Radar frequency dielectric dispersion in sand and sandstone: Implications for determination of moisture content and clay content, Water Resour. Res. 39(2), 1026. doi:10.1029/2001WR000923. 


\section{Appendix: Dataset description}

The data files are arranged in three folders:

Logging - contains borehole logs

Tracer98 - contains data for 1998 tracer test

Tracer03 - contains data for 2003 tracer test

All filenames are shown in italics below

\section{Logging file list}

BH_logging.xls - an Excel file containing gamma and induction logs in all boreholes

\section{Tracer98 file list}

inputs.xls - an Excel file containing rainfall data during the test plus a list of dates when ERT and radar data were collected

ZOP travel_times.xls - an Excel file containing 50MHz, $100 \mathrm{MHz}$ and $200 \mathrm{MHz}$ zero offset first arrivals in ns.

layout.xls - an Excel file with the borehole and ERT electrode locations.

981006.oc - ERT data file for 6-Oct-98 (background)

981010.oc - ERT data file for 10-Oct-98

981012.oc - ERT data file for 12-Oct-98

981104.oc - ERT data file for 04-Nov-98

981124.oc - ERT data file for 24-Nov-98

The format of the ERT data files is:

column 1: measurement number column2: $\mathrm{C}+$ borehole number (always 1 )

column3: $\mathrm{C}+$ electrode number column4: C- borehole number (always 1 )

column5: C- electrode number column6: $\mathrm{P}+$ borehole number (always 1 )

column7: $\mathrm{P}+$ electrode number column8: P- borehole number (always 1)

column9: P- electrode number column10: Resistance in ohms column11: Absolute resistance reciprocal error in ohms column12: Percentage resistance reciprocal error 
981005.tta - $100 \mathrm{MHz}$ MOG radar travel time file for 5-Oct-98 (background)

981006.tta - $100 \mathrm{MHz}$ MOG radar travel time file for 6-Oct-98 (background)

981009.tta - $100 \mathrm{MHz}$ MOG radar travel time file for 9-Oct-98

981010.tta - $100 \mathrm{MHz}$ MOG radar travel time file for 10-Oct-98

981011.tta - $100 \mathrm{MHz}$ MOG radar travel time file for 11-Oct-98

981012.tta - $100 \mathrm{MHz}$ MOG radar travel time file for 12-Oct-98

981016.tta - $100 \mathrm{MHz}$ MOG radar travel time file for 16-Oct-98

The format of the travel time files is:

column1: trace number

column2: Grade (not used)

column3: Tx $\mathrm{X}$ position (always 0 which refers to H-R1 in this case)

column4: Tx Y position (always 0 which refers to H-R1 in this case)

column5: Tx $\mathrm{Z}$ position in metres (negative means below ground surface)

column6: Rx X position (always $4.97 \mathrm{~m}$ which refers to H-R2 in this case)

column7: Rx Y position (always 0 which refers to H-R2 in this case)

column8: Rx $\mathrm{Z}$ position in metres (negative means below ground surface)

column9: Travel time in ns

column10 to 18 are not used.

\section{Tracer03 file list}

ZOP travel_times.xls - an Excel file containing 100MHz zero offset first arrivals in ns.

layout.xls - an Excel file with the borehole and ERT electrode locations. Note that the electrode positions are different to the 1998 tracer test.

$\begin{array}{ll}\text { 030306.oc } & \text { - ERT data file for 6-Mar-03 (background) } \\ \text { 030313.oc } & \text { - ERT data file for 13-Mar-03 } \\ \text { 030315.oc } & \text { - ERT data file for 15-Mar-03 } \\ \text { 030316.oc } & \text { - ERT data file for 16-Mar-03 } \\ \text { 030321.oc } & \text { - ERT data file for 21-Mar-03 } \\ \text { 030324.oc } & \text { - ERT data file for 24-Mar-03 } \\ \text { 030327oc } & \text { - ERT data file for 27-Mar-03 } \\ \text { 030402.oc } & \text { - ERT data file for 4-Apr-03 } \\ \text { 030416.oc } & \text { - ERT data file for 16-Apr-03 }\end{array}$

The format of the ERT data files is:

column1: measurement number

column2: $\mathrm{C}+$ borehole number (always 1 )

column3: $\mathrm{C}+$ electrode number

column4: C- borehole number (always 1)

column5: C- electrode number

column6: $\mathrm{P}+$ borehole number (always 1 ) 
column7: $\mathrm{P}+$ electrode number

column8: P- borehole number (always 1)

column9: P- electrode number

column 10: Resistance in ohms

column11: Absolute resistance reciprocal error in ohms

column12: Percentage resistance reciprocal error

030306.tta - $100 \mathrm{MHz}$ MOG radar travel time file for 6-Mar-03 (background)

030314.tta - $100 \mathrm{MHz}$ MOG radar travel time file for 14-Mar-03

030315.tta - $100 \mathrm{MHz}$ MOG radar travel time file for 15-Mar-03

030316.tta - $100 \mathrm{MHz}$ MOG radar travel time file for 16-Mar-03

030317.tta - $100 \mathrm{MHz}$ MOG radar travel time file for 17-Mar-03

030319.tta - $100 \mathrm{MHz}$ MOG radar travel time file for 19-Mar-03

030320.tta - $100 \mathrm{MHz}$ MOG radar travel time file for 20-Mar-03

030321.tta - $100 \mathrm{MHz}$ MOG radar travel time file for 21-Mar-03

030324.tta - $100 \mathrm{MHz}$ MOG radar travel time file for 24-Mar-03

030327.tta - $100 \mathrm{MHz}$ MOG radar travel time file for 27-Mar-03

030402.tta - $100 \mathrm{MHz}$ MOG radar travel time file for 04-Apr-03

030416.tta - $100 \mathrm{MHz}$ MOG radar travel time file for 16-Apr-03

The format of the travel time files is:

column1: trace number

column2: Grade (not used)

column3: Tx X position (always 5 which refers to H-R1 in this case)

column4: Tx Y position (always 0 which refers to H-R1 in this case)

column5: Tx $\mathrm{Z}$ position in metres (negative means below ground surface)

column6: Rx X position (always 0 which refers to H-R2 in this case)

column7: Rx Y position (always 0 which refers to H-R2 in this case)

column8: Rx $\mathrm{Z}$ position in metres (negative means below ground surface)

column9: Travel time in ns

column10 to 18 are not used. 


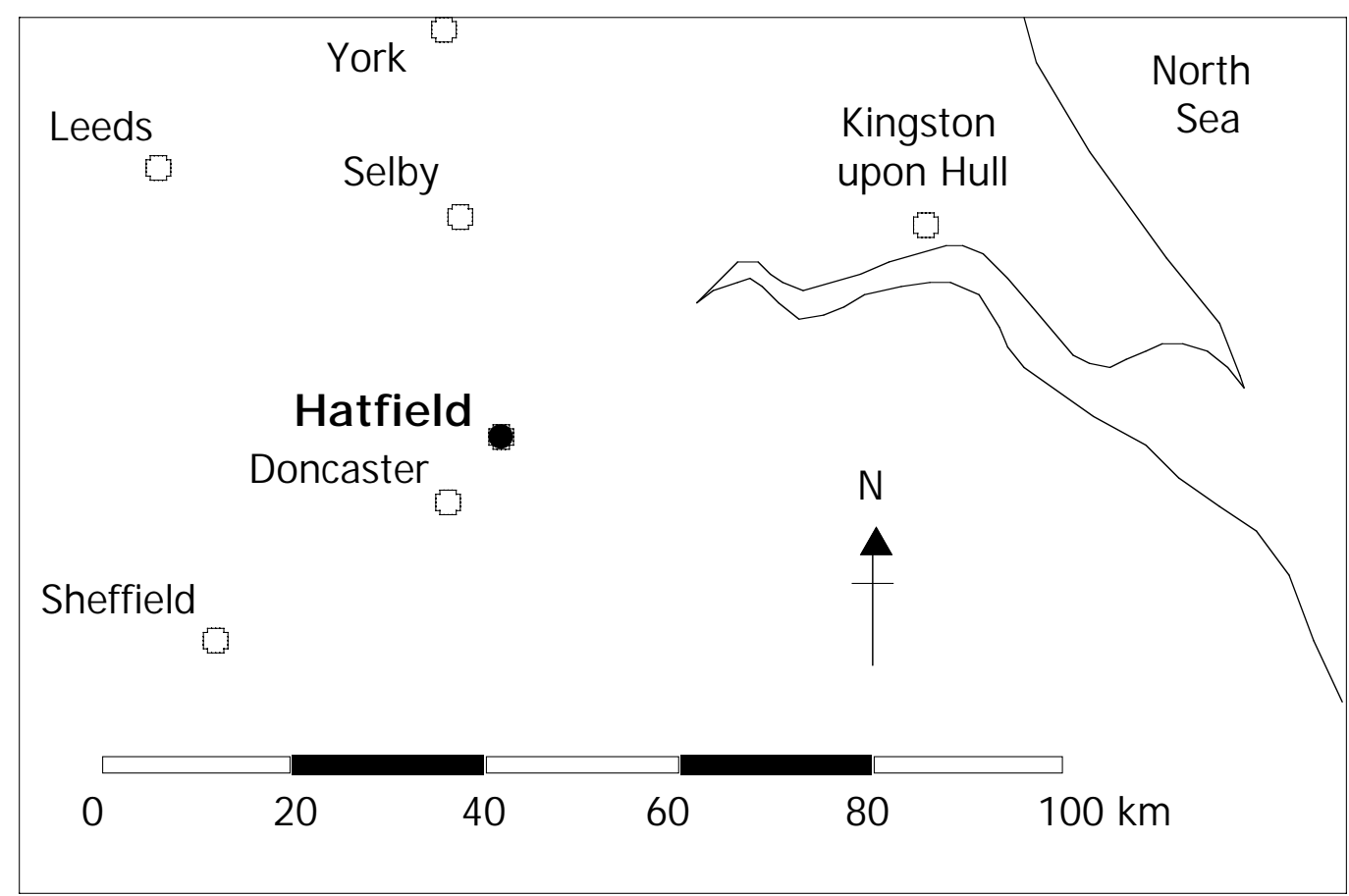

Figure 1. Site location.

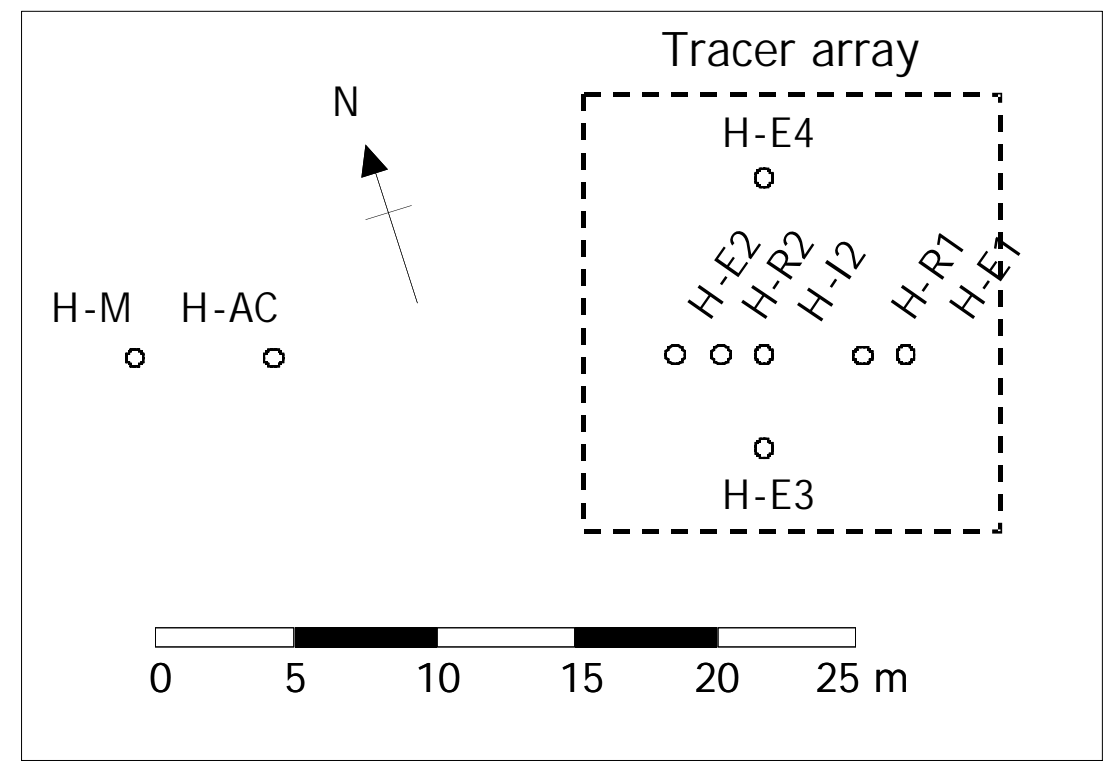

Figure 2. Field site layout. 


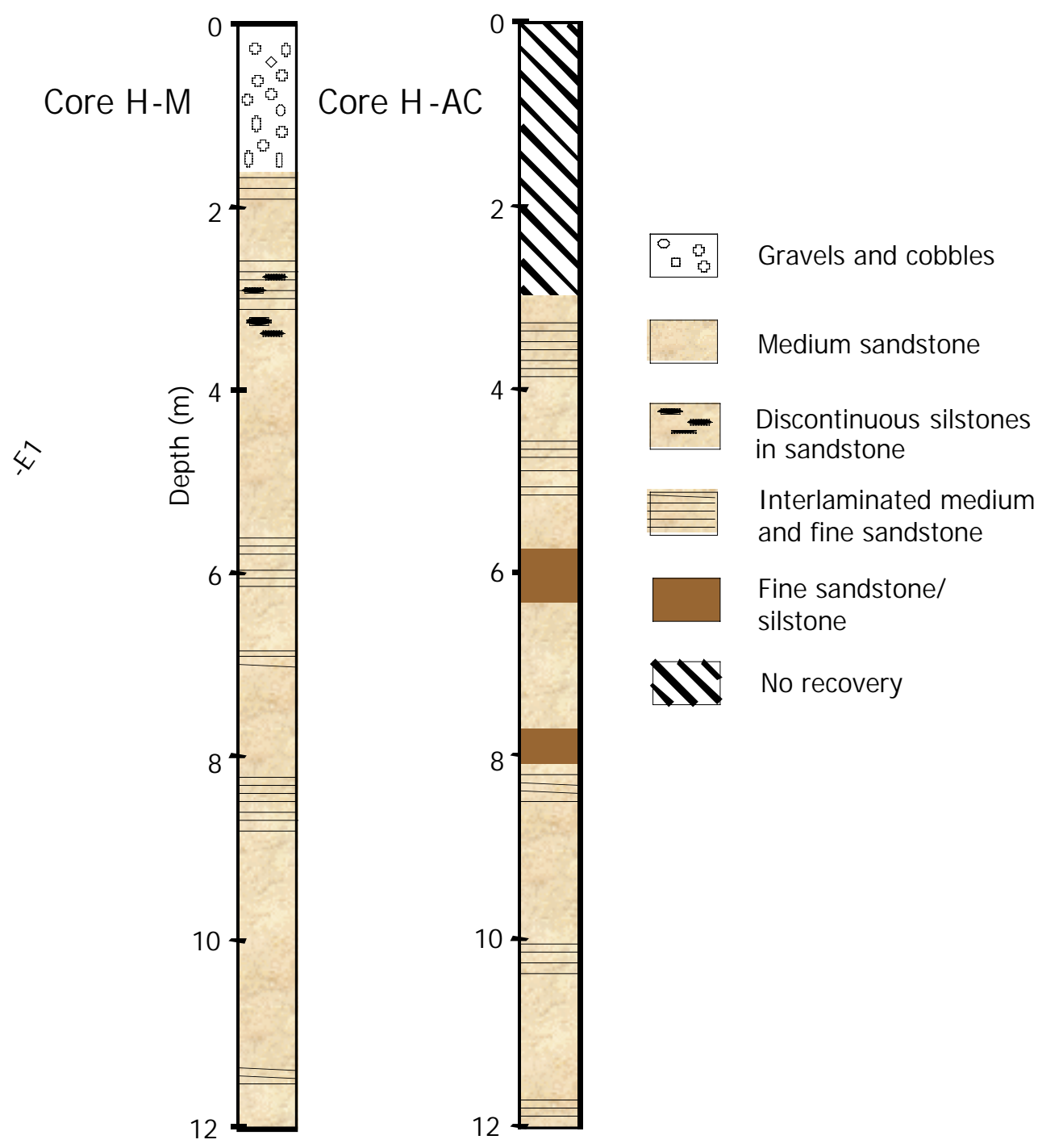

Figure 3. Core logs (supplied by Jared West, Leeds University). 


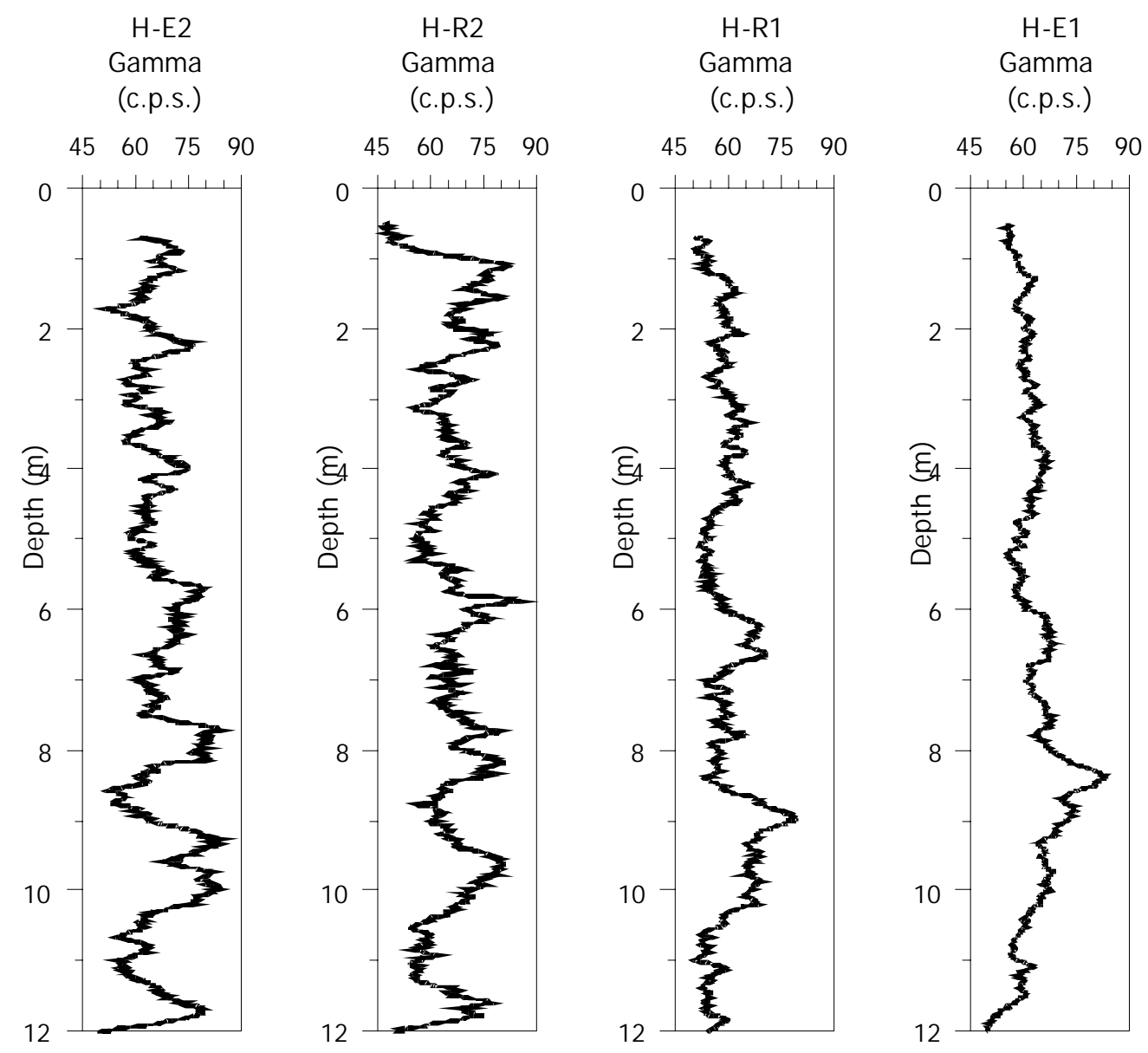

Figure 4. Natural gamma logs in boreholes H-E2, H-R2, H-R1, H-E1. 

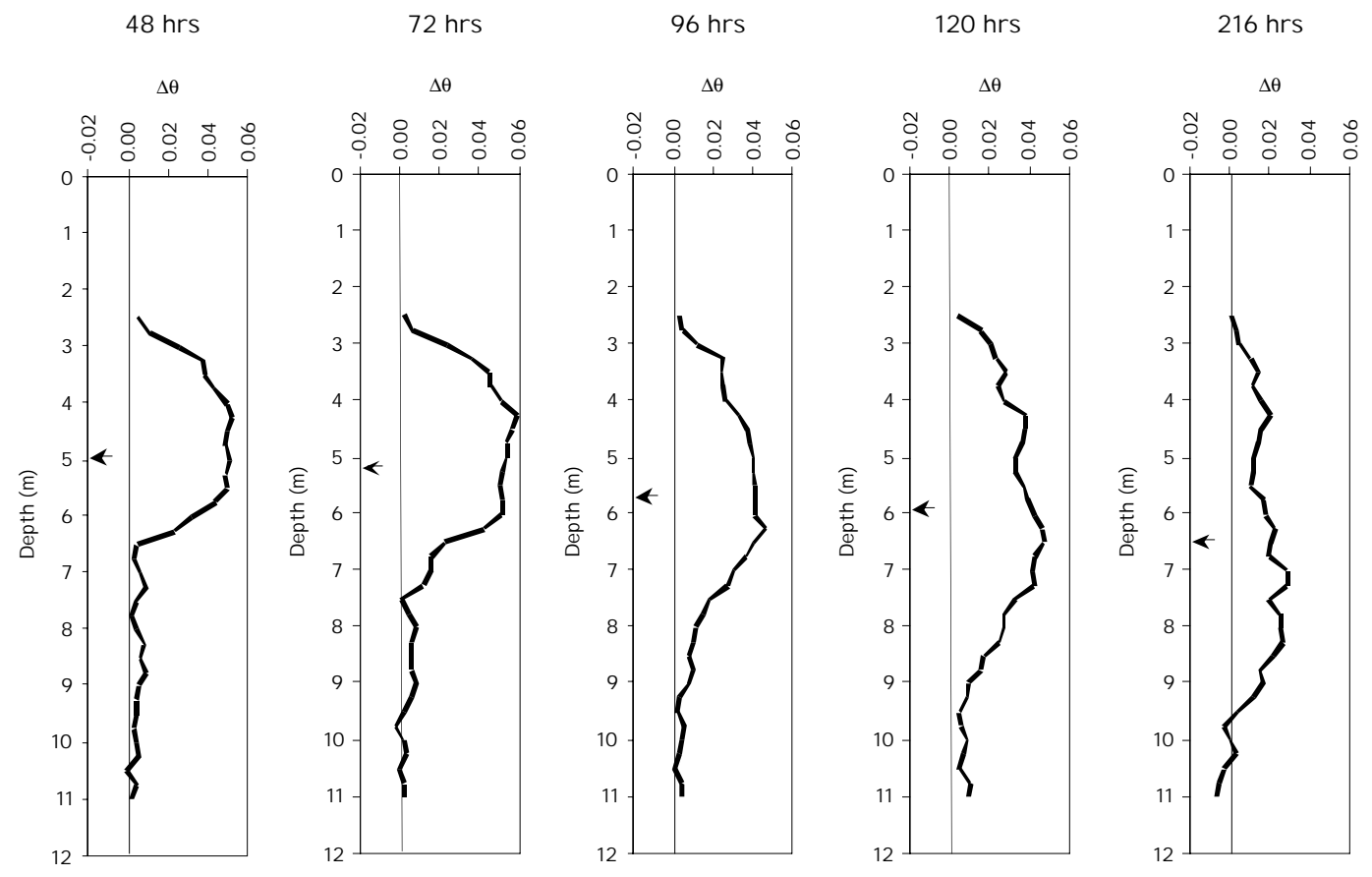

Figure 5: October 1998 tracer test: Cross-borehole radar zero offset profile results for borehole pair (H-R1, H-R2) showing change in moisture content $(\Delta \theta)$ using CRIM model at various times following injection of tracer. Horizontal arrow shows position of centre of mass of change in moisture content. 


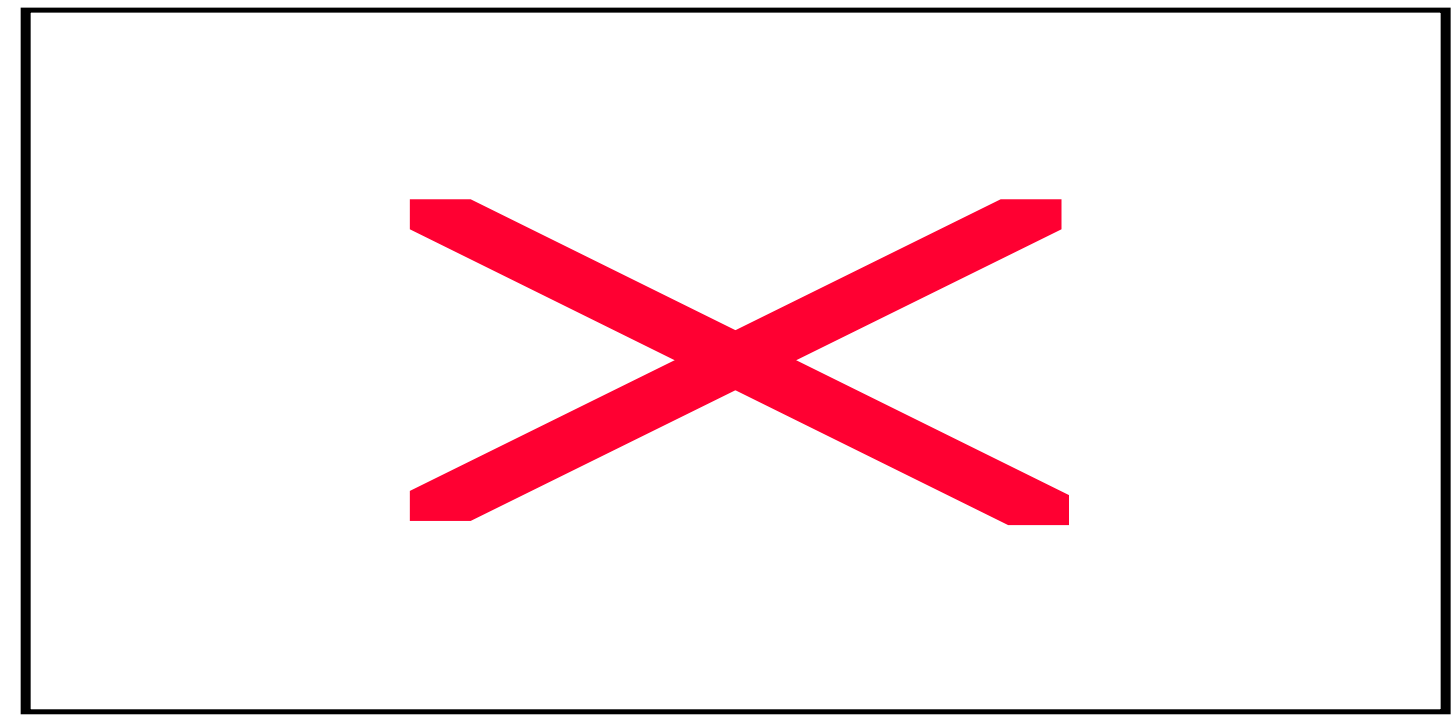

Figure 6: October 1998 tracer test: Cross-borehole 3-D ERT results showing change in moisture content following injection of tracer. Only increases in moisture content over 0.01 is shown.
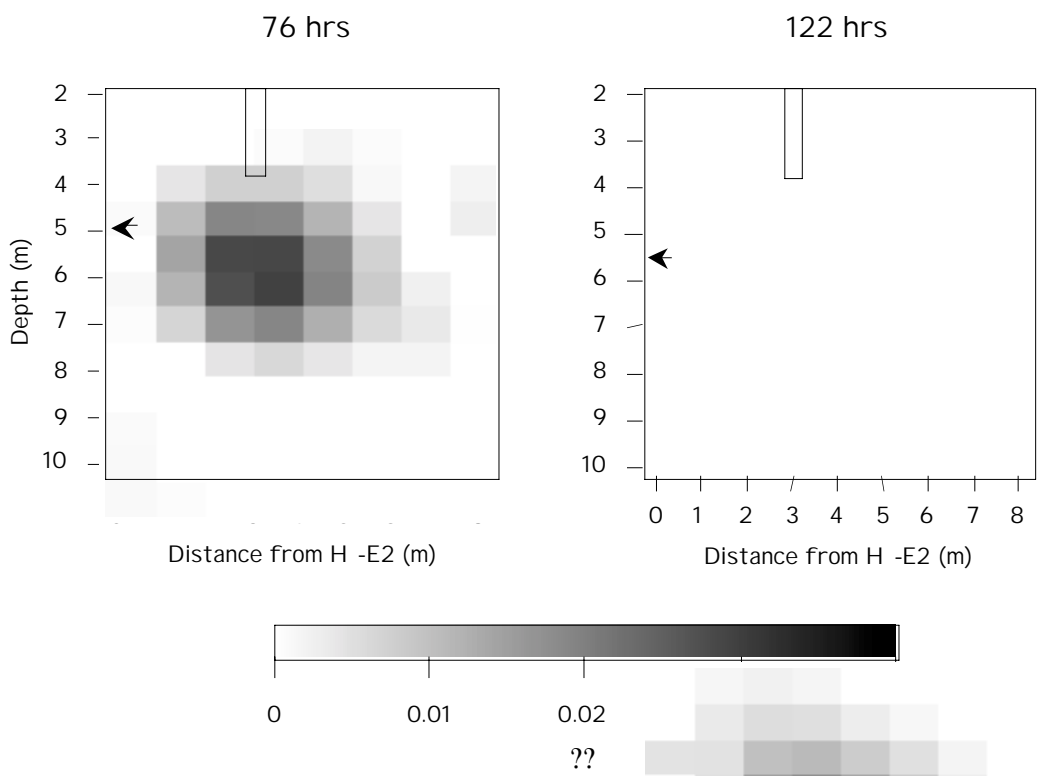

Figure 7: October 1998 tracer test: Cross-borehole 3-D ERT results showing change in moisture content between boreholes E2 and E1 at various times following injection of tracer. Horizontal arrow shows position of centre of mass of change in resistivity. Also shown is position of injection well $\mathrm{H}-\mathrm{I} 2$. 


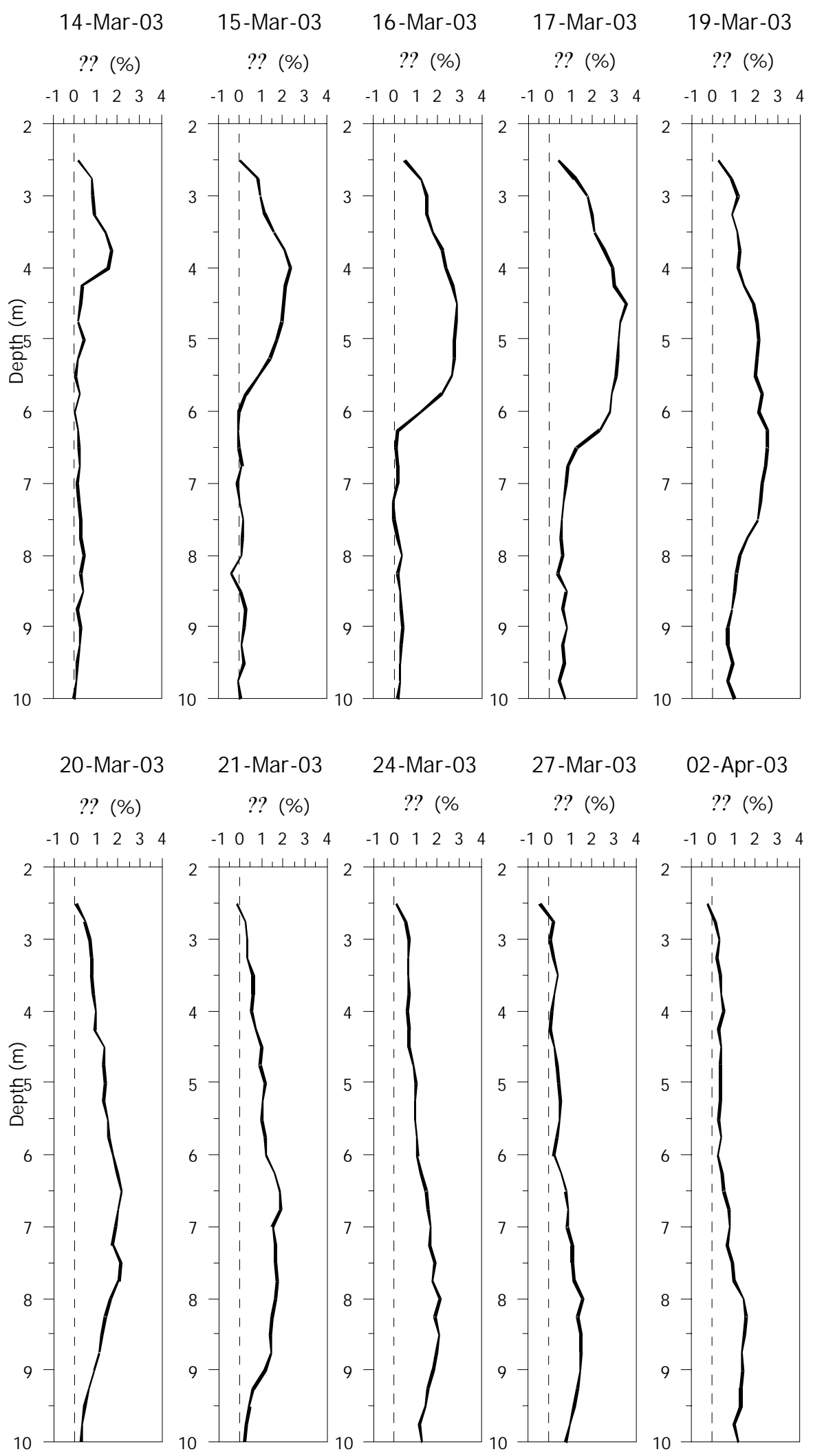

Figure 7. March 2003 tracer test: Changes in moisture content from pre-tracer conditions between boreholes H-R1 and H-R2 during tracer test, inferred from ZOP surveys. 


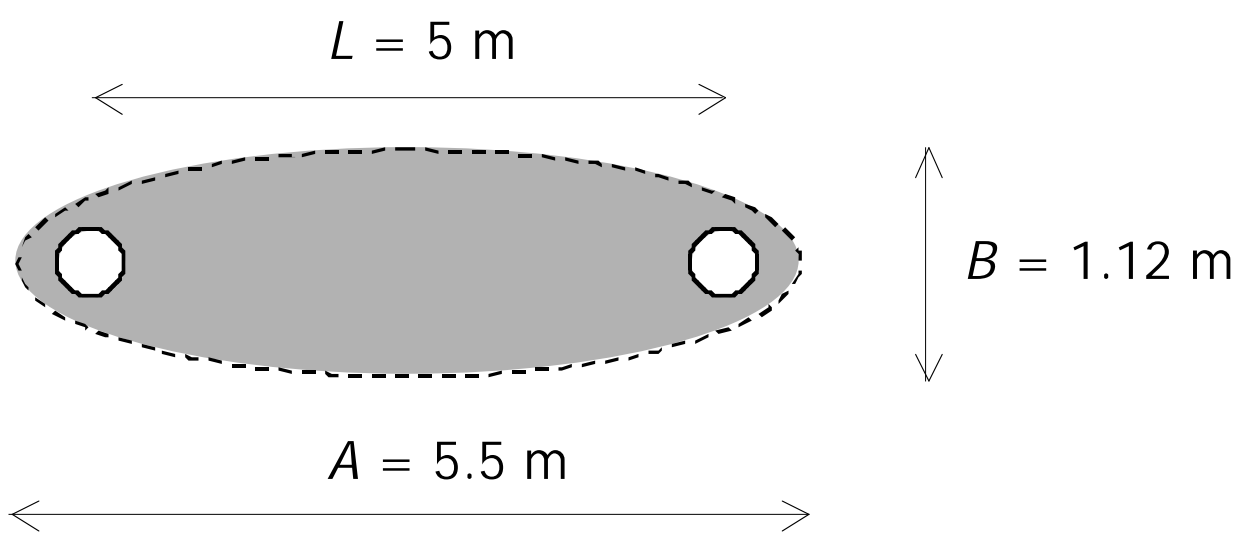

Figure 8. Definition of the Fresnel zone for borehole radar measurements. 


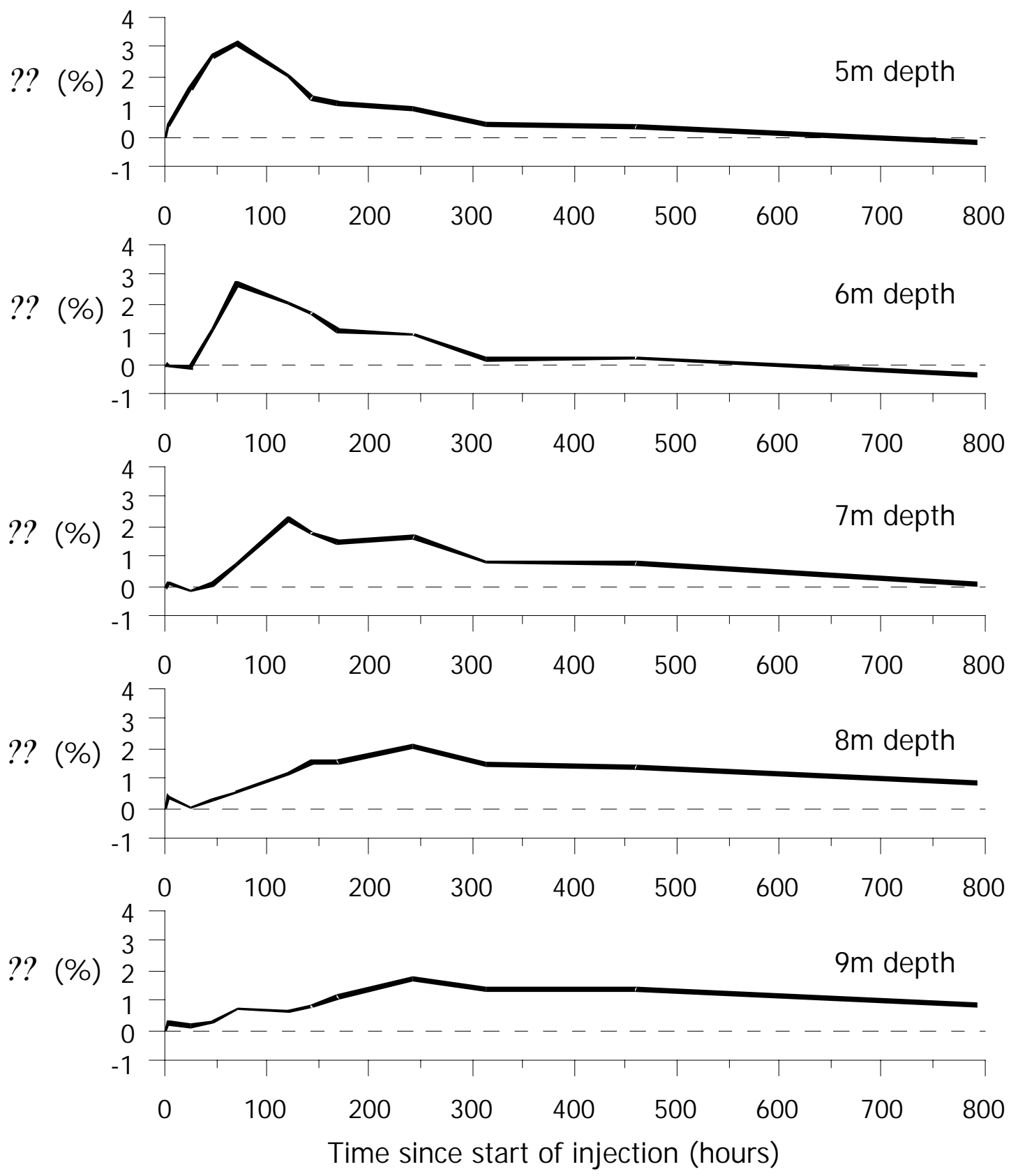

Figure 9. March 2003 tracer test: Changes in moisture content during the tracer test at specific depths, inferred from ZOP surveys. 

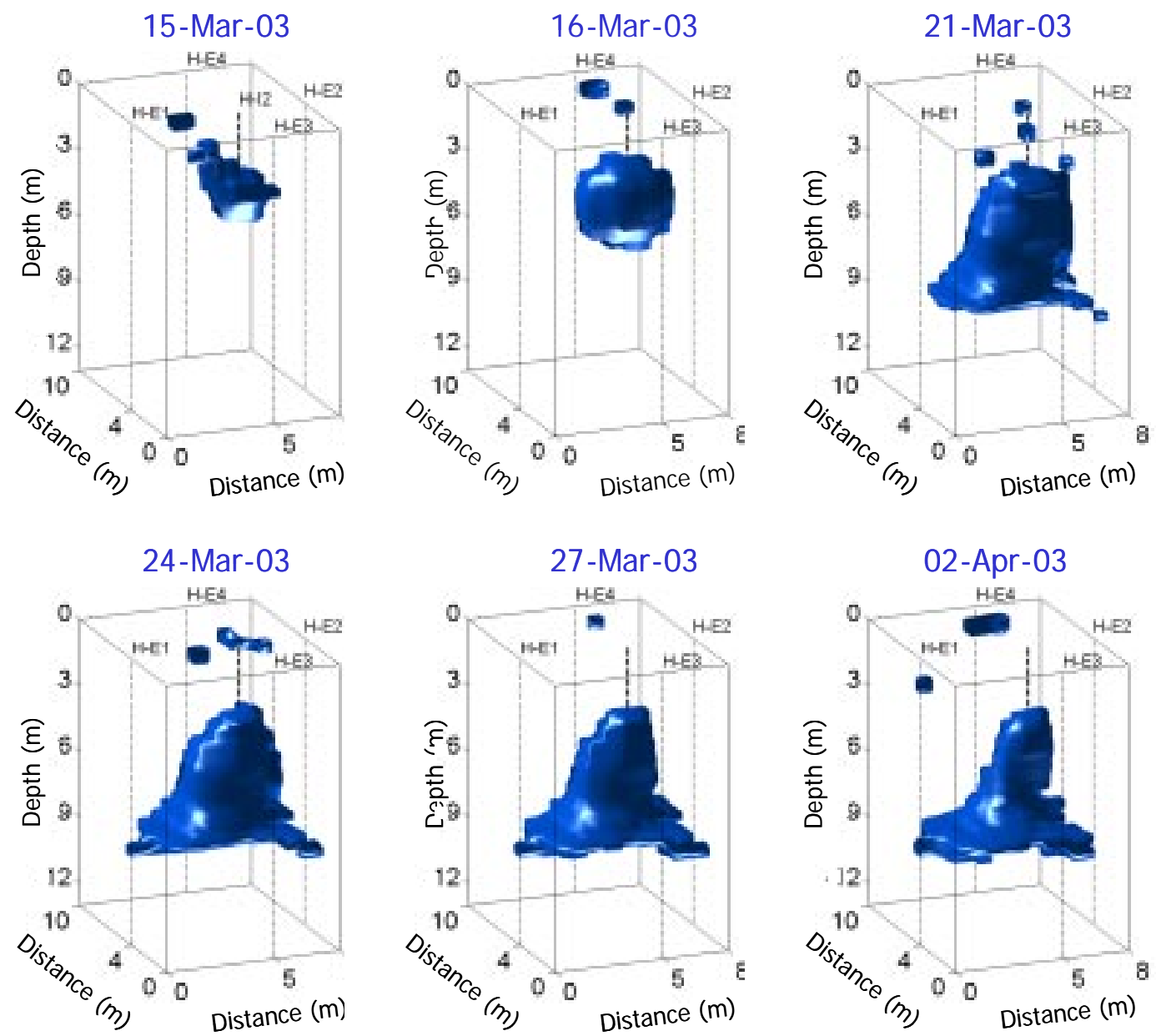

Figure 10. March 2002 tracer test: Changes in resistivity during tracer test shown as isosurfaces of $7.5 \%$ reduction in resistivity relative to pre-tracer conditions. 

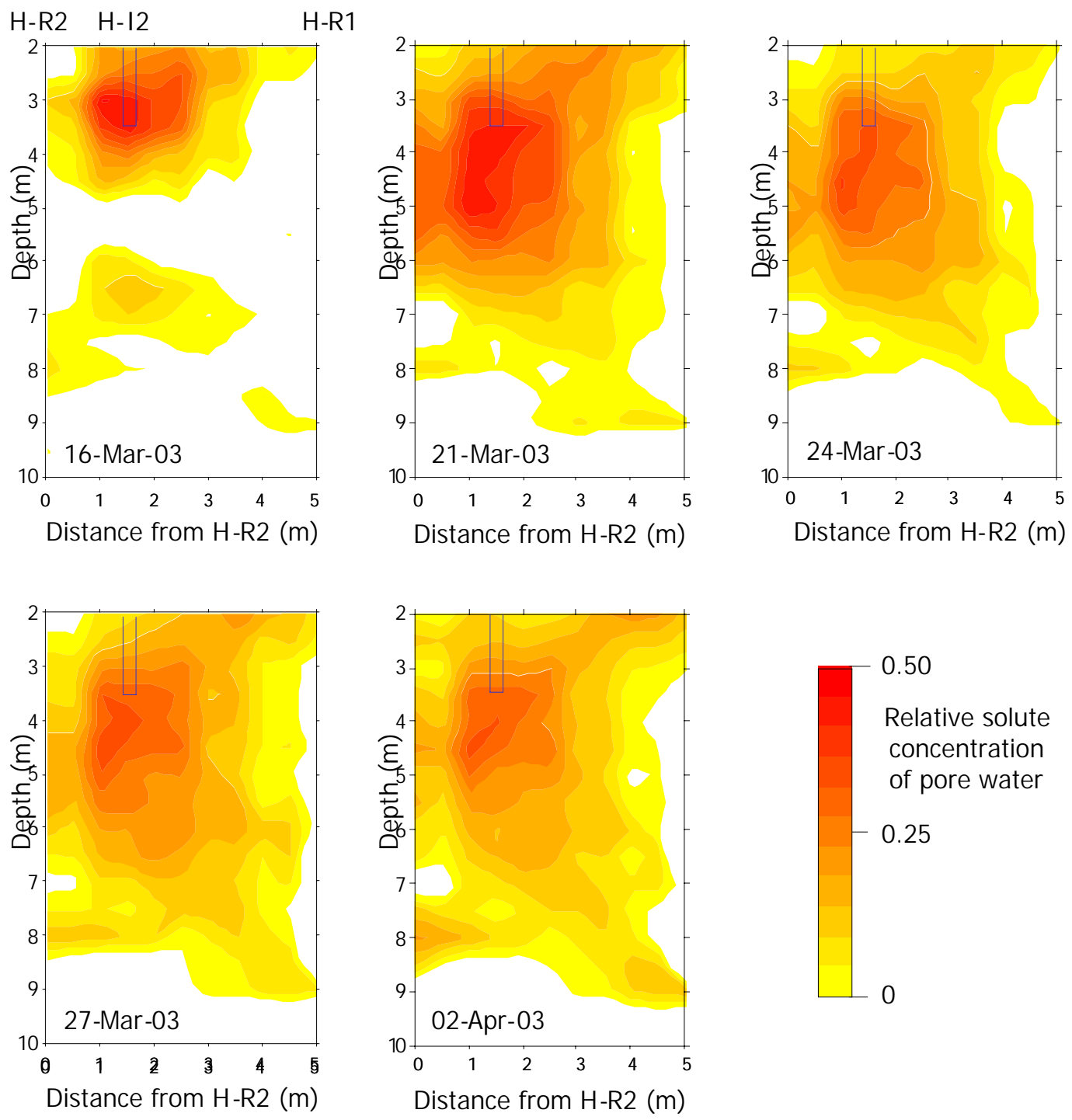

0.25

Figure 11. March 2002 tracer test: Changes in pore water solute concentration during the tracer test, inferred from radar and resistivity images. 
University of California

Lawrence Livermore National Laboratory

Technical Information Department

Livermore, CA 94551

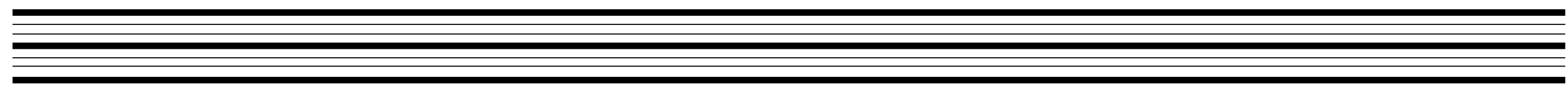

